\title{
PAST-TIME REFERENCE, TENSE, AND ASPECT PAST SIMPLE AND PRESENT PERFECT
}

\author{
Miroslava Tsvetkova*
}

\begin{abstract}
Stemming from the most common errors in the use of English tenses by Bulgarian learners, the article deals with the comparison and contrast between the Past Simple and the Present Perfect as special attention is paid to their temporal and aspectual meanings. For non-native speakers the distinction and the relationship between time, tense, and aspect can be confusing. Time can refer to the past, present, or future, tense generally describes an action or state in the present or past, while aspect is concerned with the duration and completion/incompletion of the process. The article aims at locating the study within the broader theoretical framework of how temporality is expressed linguistically and in relation to the temporal adverbials.Tests made by undergraduates of Primary Education with a Foreign Language (English) are analysed in order to interpret temporality. Various semantic restrictions typical of the perfect in English are outlined. The focus of the discussion is mainly seen from a teaching point of view.
\end{abstract}

Key words: time, tense, aspect

\section{Introduction}

Time and temporality are grammatically encoded by basic linguistic categories such as tense, mood, and aspect. 'Tense', 'aspect', and 'time' together provide a broad base for insight on the distinction between the Past Simple and the Present Perfect.

Comrie (1985, p. 9) defines tense as "the grammaticalised location in time". Hamm and Bott (2014) support the same meaning: "the grammatical means to indicate the time when an action or event occurs, or when a state or process holds".

Tense specifies when a situation takes place in relation to time because time expresses the perception of reality. This explains why a present tense can refer not only to the present, the way a past tense refers not only to past time.

\section{Background of the study}

\subsection{Research questions}

\footnotetext{
* Assist. Professor PhD at Shumen University, Department of English Studies, Shumen, Bulgaria, e-mail: m.tsvetkova@shu.bg.
} 
The aim of the paper is to locate the study within the broader theoretical framework of how temporality is expressed linguistically and in relation to the temporal adverbials. It focuses the attention on past-time reference, tense, and aspect in order to help the undergraduates of Primary Education with a Foreign Language (English) avoid the mistakes they make when using the Past Simple and the Present Perfect.

\subsection{Time and tense}

Although time and tense sound similar to Bulgarian learners of English, the two terms do not overlap. Naming Past Simple and Present Perfect learners can be embarrassed. At first glance they refer to different times, i.e. past and present. Actually, both of them refer to the past. But the present and past tenses can refer to the past and the present as well as the future time.

He visits Rome every year. (expressing a repeated action)

The train arrives at 3.15. (expressing future time)

By the same token, apart from denoting the past time, a past tense can refer to the present time. There are examples in hypothetical sentences, in reported speech, as well as in some other structures:

He got angry because he realised the truth. (denoting the past time)

If I had more money, I would travel around the world. (denoting the present time; talking about something in the present which is impossible, because it is not true)

Did you tell him you were busy? (sequence of tenses; denoting the present time)

It's time you changed your hairstyle. (denoting the present time)

From a morphological perspective, some grammarians claim that there are only two forms of the verb, the present and the past (see Quirk et al., 1985, pp.175176).

\subsection{Time and aspect}

Time refers to the moment an action takes place, whereas aspect refers to how the speaker sees the event or action. Aspect characterises the contour of the situation, such as the completion, duration, or repetition of the action.

\begin{tabular}{|l|l|}
\hline Time & Aspect \\
\hline Present & Simple \\
\hline Past & Progressive \\
\hline Future & Perfect \\
\hline
\end{tabular}




\section{Table 1. Time and aspect.}

Some grammarians consider Perfect and Progressive as the two main aspects in English. Others call Simple the indefinite aspect, which does not make clear whether the action is complete or habitual.

\subsection{Tense and aspect}

Teaching English grammar and the Present Perfect, in particular, to Bulgarian learners is a great challenge for second language teachers.

The Present Perfect is contrasted with the Past Simple since learners often mistake them because both of them refer to the past. Although both tense and aspect are related to time, there is a difference between them and it lies in the perspectives from which the situation is viewed. The Present Perfect emphasises the present effect of a past action. The Past Simple, however, focuses on the past effect. According to Huddleston and Pullum (2005), tense bridges the location time of an action or state and the time of speech (the present or past). Aspect, on the other hand, expresses the temporal properties and the way they are related to the reference time.

The study sticks to Biber's classification (Biber et al., 1999, p. 460) of the Perfect as an aspect although many grammarians classify it as tense. That is why the article compares the aspects of the Past Simple and the Present Perfect and only the latter is marked as [+perfective].

\section{Methods of analysis}

The present study employs the test method to help interpret temporality. This is a qualitative study of relevant quantitative results which means that the analysis of the results will be concentrated on the types of errors the students make concerning time, tense, and aspect.

\section{Data analysis}

The tests to be analysed are sat by undergraduates of Primary Education with a Foreign Language (English) at Shumen university. The main purpose of the study is to explain why Bulgarian learners have problems with the English Present Perfect and to suggest how it may be effectively taught. In the current study, the use of the Present Perfect is contrasted with the Past Simple.

The errors that were found were divided and presented in two sections: namely, errors which belong to the Past Simple and the Present Perfect. The total number of 72.29 errors were found with expressions of the Past Simple, whereas 43 errors were found with expressions of the Present Perfect. 
As many as 8 different substitutions were found for expressing the Past Simple: Present Simple was used instead of the Past Simple:

*I am born in Varna.

*I was born in Aytos when the $20^{\text {th }}$ century end.

One of the possible explanations why the Past Simple is substituted by the Present Simple can be the fact that the students did not master the inflections of the verbs. Another explanation is that the students use the Bulgarian equivalent, so the negative transfer is the reason for the error. L1 transfer can also be considered to be the major cause of the difficulties Bulgarian learners have using the Present Perfect in English. For example, Bulgarian learners tend to use the Past Simple in English where the Present Perfect is required.

The Past Simple and the Present Perfect are first encoded for temporal specification, that is, whether the clause is modified by some temporal adverbials. Temporally specified examples are generally outnumbered by unspecified ones.

Students suggested that durative adverbials (e.g., for three years, since 1900, all these years) or those specifying time spans (e.g., in three hours) as well as those with a strong present-time orientation (e.g., now, at present) tend to favour the Present Perfect.

On the other hand, the Past Simple often occurs with specific past-time adverbials which refer to the past time that is over and disconnected with the present (e.g., yesterday, last month, in 1990, an hour ago, at 4 o'clock, etc.) and specify the temporal location.

But when a past-time adverbial is not explicit and the remoteness should be defined in the context, then the trouble comes. The past tense is used for a completed period versus an incomplete one:

Tom Jones lived in Sunbury all his life. (complete - implies Tom Jones is dead) Tom Jones has lived in Sunbury all his life. (incomplete - Tom Jones still lives there)

The duration and completion/incompletion of the process including its beginning and end are the interpretations students fail to make.

The present perfect, on the other hand, is used for an indefinite versus a definite situation:

Have you ever gone to the Namib?

Did you go to the Namib?(He was in South Africa last month) 
Normally, durative adverbials combine with unbounded verb phrases so there is no endpoint built in, while cardinal and frequency adverbials are used with bounded verb phrases.

He has lived in London since 1984.

Tom has studied for an hour.

*Mum cooked the dinner for a second.

Lisa called Edward twice.

Sometimes the verb phrases acquire an interpretation derived from their original meaning.

Edward has been ill twice. (all his life; he is still a child)

Jason was ill twice. (repeatedly every two months)

Another common mistake derives from situations when the verb form is accompanied by time adjuncts that refer to a period of time that is still open at the moment of speaking (e.g. this week/month/year, etc.).

He has written three articles this week.

Adverbials with less distinctive patterns include temporal quantifiers (e.g., always, never, ever), adverbials expressing frequency (e.g., often, three times), recent past time (e.g., before, just, recently), or the speaker's evaluation of a situation in relation to the present (e.g., already, yet). Temporal specifiers that do not fit into these categories include today, this afternoon, and adverbial clauses led by when.

Temporal quantifiers are adverbials, which quantify over a contextually defined time span. Whentheyoccurwith the Present Perfect, the boundary of the contextually defined time span coincides with the present moment.

He has never been to Paris. (This is still his dream)

I have always dreamt of being a princess. (Although I am not a child, this is still my dream)

Temporal quantifiers differ from durative adverbials in that they make reference to the present implicitly. The exact duration or temporal location of the present is recovered from the shared knowledge of the interlocutors, whereas in the case of for- and since-adverbials, such information is specified in the lexical semantics.

Then transitivity was encoded to investigate signs of the Present Perfect expanding from transitive to nontransitive contexts. Verbs were classified depending on whether they were transitive or intransitive. The category of transitives includes monotransitive verbs (e.g., feed [the chickens]), ditransitive 
verbs (e.g., give [him a present]), and complex transitive verbs (e.g., consider [it right]). Nontransitives include copular verbs (e.g., be, become, get, feel) and intransitive verbs (e.g., smile, die). Phrasal verbs (e.g., take away, go down), on the other hand, can be both transitive and intransitive.

Negation was also encoded. Negative clauses contain either clausal or subclausal negators (e.g., not yet, never, nobody, nowhere, no longer).

He has not finished yet.

Nobody has resisted it.

I have never eaten raw fish.

The errors in the tests come from the fact that the Present Perfect was not always situated in the time between 'now' and 'at any time' within the time span and the Past Simple was not restricted to the time between now (the present) and then (the past). In order to interpret the errors, I also had into account the meanings of the Present Perfect following Comrie (1976). These four readings of the perfect can make its use easier and more comprehensible for the learners.

The continuative perfect explained the erroneous use of the Past Simple in some sentences. The present moment plays an important role here because the state or the event has not only started in the past but persisted until the moment of speaking or writing (the present time) (Comrie, 1976).

I have known Mr. Johnson since last year. (I still know him)

Excluding the duration of the process, students made the mistake to use the Past Simple instead:

*I knew Mr. Johnson since last year.

A lot of students missed the point that since last year gave the starting point of the state but the situation was not over. Last year is probably the specific past-time adverbial, which makes them use the Past Simple for a completed situation.

As in the continuative perfect, the present is part of the experiential (or existential) perfect, too. The experiential perfect expresses one or more experiences up to the present time (Comrie, 1976). It denotes an event that could recur at present: Have you seen "The Star Wars"? (The movie is still on and you can go and see it)

A specific change of state is involved in the resultative perfect:

She has locked the door. (the door is locked now)

Emily has torn her dress. (the dress is torn now) 
We have walked for hours. (We were walking up to the present moment and now we are tired)

Students made less mistakes with this use of the Present Perfect. A probable reason for this is that this case is described and discussed in textbooks.

The semantic relation between the resultative perfect and the past is another reason for the errors. The resultative perfect indicates a state or event that happened before the present moment (Comrie, 1976). It expresses a situation located in the past but simultaneously related to the present.

As the name of the fourth reading says 'the perfect of recent past', it is used for recent past situations (Comrie, 1976):

We have just had lunch.

I haven't read many magazines recently.

Adverbs like recently and just carry this meaning and they reminded the students they have to use the Present Perfect.

\section{Results/ Key findings}

The study concluded that

- aspect, both grammatical and lexical, and tense are together parts of the linguistic study in the time domain.

- the relation between tense and aspect, in the Present Perfect in the current study, is more than the sum of their parts. The Present Perfect bridges the gap between the past and the present.

- temporality can be expressed through adverbials or they can be neglected in their interaction with the above-mentioned grammatical categories.

- the Present Perfect is ambiguous with respect to its four interpretations (following Comrie, 1976).

\section{Conclusion}

Although, the use of time and tense was central in this study, the perfective aspect was also included because tense and aspect are closely related.

Although there was a view which held that grammar should be taught and learnt naturally and implicitly (Krashen, 1982), the author supports the idea that the boundary between the Past Simple and the Present Perfect should be differentiated, otherwise, themessage could be misinterpreted. For this reason, various semantic restrictions typical of perfect readings (Comrie, 1976) were outlined, too. To conclude, explicit instruction can help implicit knowledge to be developed into producing meaningful sentences in communicative situations. 


\section{Implications}

The four readings suggested by Comrie (1976) lead to a different interpretation of the errors related to the Present Perfect, which in turn leads to better students' learning outcomes.The findings outlined in the survey results can help for the easier comprehension of the grammatical categories.

\section{References:}

Biber et al. (1999). Biber, D., Johansson, S., Leech, G., Conrad, S., \& Finegan, E. Longman grammar of spoken and written English. Harlow: Pearson Education Limited. Pp. 460.

Comrie, B. (1976). Aspect: An introduction to the study of verbal aspect and related problems. Cambridge: Cambridge University Press.

Comrie, B. (1985). Tense. UK, Cambridge: Cambridge University Press.

Hamm, F. \& Bott, O. (2014). Tense and aspect. The Stanford Encyclopedia of Philosophy. (2018, June 4) Retrieved from https://plato.stanford.edu/entries/tense-aspect/

Huddleston, R. \& Pullum, G. (2005). A student's introduction to English grammar. Cambridge: Cambridge University Press.

Krashen, S. (1982). Principles and practice in second language acquisition. Vol. 2. Pergamon: Oxford.

Quirk et al. (1985). Quirk, R., Greenbaum, S., Leech, G., \& Svartvik, J. A comprehensive grammar of the English language. Longman Inc, New York. 175-176. 